\title{
Association between brachial-ankle pulse wave velocity and 3-year mortality in community-dwelling older adults
}

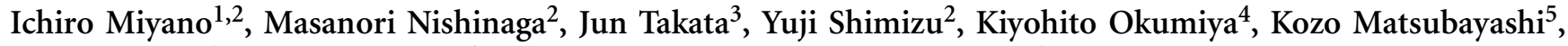 \\ Toshio Ozawa ${ }^{2}$, Tetsuro Sugiura ${ }^{6}$, Nobufumi Yasuda ${ }^{1}$ and Yoshinori Doi ${ }^{2}$
}

With aging, arterial stiffness increases and results in cardiovascular diseases. Recently, high brachial-ankle pulse wave velocity (baPWV), measured using a new noninvasive device to estimate arterial stiffness, was reported to be associated with the prevalence of cardiovascular diseases. The purpose of this study was to clarify the association between baPWV with 3-year mortality in community-dwelling older adults and to determine the cutoff value of baPWV in terms of mortality. A total of 530 subjects aged 65 years or older (men/women, 207:323; mean age, 76 years) participated. They were dichotomized by the median value of baPWV. Within 3 years, 30 deaths occurred, including 11 cardiovascular deaths. The high-baPWV group had a higher incidence of total deaths (high-baPWV group vs. low-baPWV group, 8.3 vs. 3.0\%, respectively) and cardiovascular deaths (high-baPWV group vs. lowbaPWV group, 3.8 vs. $0.4 \%$, respectively). A high-baPWV level was associated with an increased risk of 3-year total mortality after adjustment for age, sex and systolic blood pressure (hazard ratio for high baPWV vs. low baPWV $=2.98,95 \% \mathrm{Cl}=1.25-7.07$ ) and with an increased risk of 3-year cardiovascular mortality (hazard ratio for high baPWV vs. low baPWV $=10.01,95 \% \mathrm{Cl}=1.21-82.49$ ). A receiver-operating characteristic curve showed that the optimal cutoff value of baPWV for total mortality was $19.63 \mathrm{~m} \mathrm{~s}^{-1}$, and for cardiovascular mortality it was $19.63 \mathrm{~m} \mathrm{~s}^{-1}$. This study provides a preliminary finding that assessment of arterial stiffness by baPWV might be a useful method to predict mortality risk in community-dwelling older adults. Large longitudinal studies for extended periods of time are necessary to confirm the association.

Hypertension Research (2010) 33, 678-682; doi:10.1038/hr.2010.56; published online 30 April 2010

Keywords: arterial stiffness; mortality; older adults; pulse wave velocity

\section{INTRODUCTION}

Arterial stiffness increases with advancing age and is known to lead to cardiovascular disease (CVD). ${ }^{1}$ It is important to assess arterial stiffness in older adults because CVDs, such as stroke and heart disease, are the major causes of death in these individuals. Pulse wave velocity (PWV) is known to be an indicator of arterial stiffness. ${ }^{2}$ Aortic PWV, as assessed by determining carotid-femoral PWV (cfPWV), has been reported to be associated with an increased risk of total or cardiovascular mortality in clinical populations, such as patients with end-stage renal disease, ${ }^{3}$ hypertension ${ }^{4,5}$ or diabetes ${ }^{6}$ as well as in the general population. ${ }^{7-10}$ Of the previous studies, only one examined this association in community-dwelling older adults. ${ }^{7}$

Brachial-ankle PWV (baPWV) can be measured with a simple and noninvasive device that estimates arterial stiffness. Cross-sectional studies have reported an association between high baPWV and prevalence of cardiovascular risk factors, ${ }^{11,12}$ presence of coronary artery disease in male patients, ${ }^{13}$ presence of cerebrovascular disease in asymptomatic community-dwelling older persons ${ }^{14}$ and in hypertensive patients aged 50 years or older. ${ }^{15}$ However, there have been few longitudinal reports about the relationship between baPWV and mortality. ${ }^{16-18}$ One study suggested that increases in baPWV were associated with an elevated risk of cardiovascular mortality in 298 community-dwelling older adults, but the optimal cutoff value of baPWV was not shown. ${ }^{17}$

The purpose of this study was to evaluate the relationship between baPWV and 3-year mortality and to determine the optimal cutoff value of baPWV in terms of mortality among community-dwelling older adults.

\section{METHODS}

Study population

All subjects were registered in the Kahoku longitudinal study, which was designed to prolong healthy life expectancy by providing health screening, counseling and educational services to older persons living in Kahoku, a rural town in Japan. ${ }^{19,20}$ In this community of 5596 residents, $2092(37.4 \%)$ were

\footnotetext{
${ }^{1}$ Department of Public Health, Kochi Medical School, Nankoku, Japan; ${ }^{2}$ Department of Medicine and Geriatrics, Kochi Medical School, Nankoku, Japan; ${ }^{3}$ The Center to Promote Creativity in Medical Education, Kochi Medical School, Nankoku, Japan; ${ }^{4}$ Research Institute for Humanity and Nature, Kyoto, Japan; ${ }^{5}$ The Center for Southeast Asian Studies, Kyoto University, Kyoto, Japan and ${ }^{6}$ Department of Laboratory Medicine, Kochi Medical School, Nankoku, Japan

Correspondence: Dr I Miyano, Department of Public Health, Kochi Medical School, Oko-cho, Nankoku-shi, Kochi 783-8505, Japan.

E-mail: miyanoi@kochi-u.ac.jp
}

Received 25 September 2009; revised 20 January 2010; accepted 17 February 2010; published online 30 April 2010 
aged 65 years and older in 2000. Each year from 2000 to 2003, every individual aged 65 years or older was invited to the annual health checkup organized by the municipal health center. Without considering duplicates, the number of persons who participated in the checkup was 348 in 2000, 337 in 2001, 384 in 2002 and 361 in 2003 . The first visit to the checkup service was defined as entry into the present longitudinal study. Of the 577 individuals who entered the study, 18 who had lumbar pain and gibbosity were excluded because measurement of baPWV was not applicable. The remaining 559 individuals (220 men and 339 women; mean age \pm s.d. at entry, $76.6 \pm 5.6$ years) $-26.7 \%$ of the number of Kahoku residents aged 65 years or older in 2000-were invited to have their baPWV measured. Of these 559 subjects, 29 were excluded; 15 had atrial fibrillation, 5 had a medical history of arteriosclerosis obliterans and 9 had an abnormal ankle/brachial pressure index of less than 0.9 as determined by plethysmography. Therefore, the effective sample size of this study was 530 subjects (207 men and 323 women; mean age at entry, $76.4 \pm 5.6$ years).

\section{Ethical consideration}

Written informed consent was obtained from each person at entry into the study. The study protocol was approved by the research ethics committee of Kochi Medical School, Kochi University, Japan.

\section{Study variables}

Medical history and examinations. Medical history was self-reported and confirmed by a physician at the baseline health checkup. Participants were defined as having a medical history of CVD if they had a history of stroke or heart disease such as ischemic heart disease, heart failure or arrhythmia. Body height and weight were measured in the health checkup at entry into the study. Body mass index was defined as weight $(\mathrm{kg})$ divided by the square of height $\left(\mathrm{m}^{2}\right)$. Blood pressure (BP) measurements were performed in the morning in the health checkup at study entry. BP and pulse rate were recorded twice in the upper arm with an appropriately sized cuff at the level of the heart with the subject in a sitting position after a rest of at least $5 \mathrm{~min}$, using an autosphygmomanometer (BP-203I; Colin Co., Komaki, Japan) according to the cuffoscillometric method. For the analysis, we used an average of two measurements for BP and pulse rate.

\section{Brachial-ankle pulse wave velocity measurements}

baPWV was automatically measured using a form PWV/ABI instrument (Colin Co.), as previously described. ${ }^{11,21}$ This device has four cuffs matched with oscillometric sensors, and the cuffs were wrapped around the upper arms and the ankles. The volume pulse forms of the bilateral brachial and tibial arteries were monitored during continuous deflation of the cuffs. The baPWV value was calculated by time-phase analysis of the right brachium and ankle and the left brachium and ankle, respectively. baPWV was measured after the subject had lain supine for at least $5 \mathrm{~min}$. Measurements were performed twice, consecutively. An average of two baPWV measurements was used. Because there was a significant positive correlation between left and right baPWV $(r=0.954, P<0.001)$, the right baPWV value was used in this study.

The participants were dichotomized according to a median value of baPWV. Those with baPWV $<18.675 \mathrm{~ms}^{-1}$ ( $n=265$ ) formed the low-baPWV group, and the subjects with baPWV $\geqslant 18.675 \mathrm{~m} \mathrm{~s}^{-1}(n=265)$ constituted the highbaPWV group.

\section{Laboratory variables}

All participants had blood drawn in the health checkup at entry into this study. The samples were placed in cold storage immediately after collection and were analyzed within $48 \mathrm{~h}$. Blood sugar, hemoglobin Alc, total cholesterol, highdensity lipoprotein cholesterol, triglyceride, hemoglobin and albumin levels were determined.

\section{Follow-up survey for prognosis}

Survivorship of the participants for 3 years from entry into the study was followed. No study participant moved out of the municipality during the period. For those who died, we recorded the cause of death from the death certificate submitted to the municipality. Causes of death were coded according to the International Classification of Diseases, ninth edition.

\section{Statistical analysis}

All continuous variables were expressed as the mean \pm s.d. The mean values between the two groups were compared using the Student's $t$-test. The $\chi^{2}$-test was used to compare the proportions of specific categories for categorical variables. The Kaplan-Meier method was used to estimate unadjusted survival curves of the two baPWV groups. The log-rank test was used to compare the unadjusted survival curves. A Cox proportional hazards model was used to describe the association between baPWV and mortality while adjusting for age, sex and BP measures. A receiver-operating characteristic (ROC) curve analysis was performed to identify the optimal cutoff value of baPWV for predicting total mortality and cardiovascular mortality. The value with the highest sum of sensitivity and specificity was used as the optimal cutoff value. $P$-values $<0.05$ were considered statistically significant. All analyses were performed using SPSS 15.0J for Windows (SPSS Japan Inc., Tokyo, Japan).

\section{RESULTS}

\section{Baseline characteristics}

The mean value of baPWV was $18.90 \pm 3.95 \mathrm{~m} \mathrm{~s}^{-1}$ in all subjects. There was no significant difference in the means of baPWV between men and women (men, $18.81 \pm 4.01 \mathrm{~m} \mathrm{~s}^{-1}$; women, $18.97 \pm 3.92 \mathrm{~m} \mathrm{~s}^{-1}$, $P=0.647)$. Table 1 shows the baseline characteristics according to the baPWV groups. The high-baPWV group was older and had a higher proportion of subjects taking antihypertensive medication than the low-baPWV group. There were no significant differences in body mass index, the proportion of current smokers, the use of medications for diabetes mellitus and hyperlipidemia or history of CVDs between the two groups. Systolic BP (SBP), diastolic BP, pulse pressure and pulse rate were higher in the high-baPWV group as compared with the low-baPWV group. No significant difference was found in the blood test results between the two groups.

\section{Three-year mortality according to baPWV}

In the 3 years after the onset of the study, 30 persons died, 10 of whom died as a result of CVDs. Table 2 shows the number and percentage of all-cause and cause-specific deaths during the 3 years. The highbaPWV group had higher proportions of both total deaths and deaths due to CVDs. There were no significant differences in the proportions of deaths due to other causes.

Kaplan-Meier curves showed that the high-baPWV group had a significantly higher probability of overall mortality (Figure 1a) and also of cardiovascular mortality (Figure 1b). After adjustment for age, sex and SBP, a high-baPWV level was significantly associated with an increased risk of 3-year total mortality (adjusted $\mathrm{HR}=2.98,95 \%$ $\mathrm{CI}=1.25-7.07$ ) and cardiovascular mortality (adjusted $\mathrm{HR}=10.01$, 95\% $\mathrm{CI}=1.21-82.49$ ) (Table 3). When baPWV was treated as a continuous variable, a $1 \mathrm{~m} \mathrm{~s}^{-1}$ increase in baPWV was significantly associated with an increased risk of 3-year total mortality (adjusted $\mathrm{HR}=1.09,95 \% \mathrm{CI}=1.00-1.18$ ) and cardiovascular mortality (adjusted $\mathrm{HR}=1.12,95 \% \mathrm{CI}=1.01-1.25)$ after adjustment for age, sex and SBP. After adjustment for antihypertensive medication use in place of SBP, a high-baPWV level was still associated with an increased risk of 3-year total mortality (adjusted $\mathrm{HR}=2.66,95 \% \mathrm{CI}=1.17-6.05$ ) and cardiovascular mortality (adjusted $\mathrm{HR}=8.53,95 \% \mathrm{CI}=1.07-67.76$ ). This association remained after adjustment for pulse pressure in place of SBP (total mortality: adjusted $\mathrm{HR}=2.68,95 \% \mathrm{CI}=1.16-6.15$; cardiovascular mortality: adjusted $\mathrm{HR}=9.09,95 \% \mathrm{CI}=1.14-72.65)$. After adjustment for pulse rate in place of SBP, this association again remained (total mortality: adjusted $\mathrm{HR}=2.45,95 \% \mathrm{CI}=1.07-5.62$; cardiovascular mortality: adjusted $\mathrm{HR}=8.48,95 \% \mathrm{CI}=1.07-67.45)$, as well as after adjustment for medical history of CVD in addition to age, sex, and SBP (total mortality: adjusted $\mathrm{HR}=2.97,95 \% \mathrm{CI}=1.25-7.09$; cardiovascular mortality: adjusted $\mathrm{HR}=9.01,95 \% \mathrm{CI}=1.08-74.90)$. 
Table 1 Baseline characteristics according to the level of baPWV

\begin{tabular}{|c|c|c|c|}
\hline & $\begin{array}{c}\text { Low baPWV } \\
(\mathrm{n}=265)\end{array}$ & $\begin{array}{c}\text { High baPWV } \\
(\mathrm{n}=265)\end{array}$ & P-value \\
\hline Age (years) & $75.1 \pm 5.4$ & $77.7 \pm 5.5$ & $<0.001$ \\
\hline Men/women & $103 / 162$ & $104 / 161$ & 1.000 \\
\hline Body mass index $\left(\mathrm{kg} \mathrm{m}^{-2}\right)$ & $23.0 \pm 3.4$ & $23.1 \pm 3.6$ & 0.857 \\
\hline Current smoking, $n(\%)$ & $32(12.1)$ & $25(9.4)$ & 0.400 \\
\hline Antihypertensive medication, $n(\%)$ & $94(35.5)$ & $133(50.2)$ & 0.001 \\
\hline Antihyperglycemic medication, $n(\%)$ & $16(6.0)$ & $23(8.7)$ & 0.318 \\
\hline Antihyperlipidemic medication, $n(\%)$ & $32(12.1)$ & 29 (10.9) & 0.786 \\
\hline History of CVD, $n(\%)$ & $30(11.3)$ & $27(10.2)$ & 0.779 \\
\hline Systolic blood pressure $(\mathrm{mm} \mathrm{Hg})$ & $138.9 \pm 26.4$ & $154.4 \pm 21.8$ & $<0.001$ \\
\hline Diastolic blood pressure $(\mathrm{mm} \mathrm{Hg})$ & $77.7 \pm 10.8$ & $85.5 \pm 11.5$ & $<0.001$ \\
\hline Pulse pressure $(\mathrm{mm} \mathrm{Hg})$ & $61.2 \pm 24.0$ & $68.9 \pm 17.2$ & $<0.001$ \\
\hline Pulse rate (b.p.m.) & $70.8 \pm 11.7$ & $76.3 \pm 12.7$ & $<0.001$ \\
\hline Blood sugar (mg per $100 \mathrm{ml}$ ) & $114.8 \pm 27.5$ & $117.9 \pm 31.1$ & 0.225 \\
\hline Hemoglobin A1c (\%) & $5.3 \pm 0.6$ & $5.4 \pm 0.8$ & 0.144 \\
\hline Total cholesterol (mg per $100 \mathrm{ml}$ ) & $194.7 \pm 30.5$ & $198.6 \pm 35.6$ & 0.184 \\
\hline HDL cholesterol (mg per $100 \mathrm{ml}$ ) & $52.7 \pm 13.5$ & $50.7 \pm 13.5$ & 0.089 \\
\hline Triglyceride (mg per $100 \mathrm{ml}$ ) & $128.9 \pm 84.5$ & $141.9 \pm 81.3$ & 0.072 \\
\hline $\mathrm{baPWV}\left(\mathrm{m} \mathrm{s}^{-1}\right)$ & $15.89 \pm 1.80$ & $21.92 \pm 3.13$ & $<0.001$ \\
\hline
\end{tabular}

Abbreviations: baPWV, brachial-ankle pulse wave velocity; CVD, cardiovascular disease; HDL, high-density lipoprotein.

Low baPWV, $<18.675 \mathrm{~m} \mathrm{~s}^{-1}$; high baPWV, $\geqslant 18.675 \mathrm{~ms}^{-1}$.

Table 2 Three-year cause-specific mortality according to the level of baPWV

\begin{tabular}{lccc}
\hline & $\begin{array}{c}\text { Low baPWV } \\
(\mathrm{n}=265)\end{array}$ & $\begin{array}{c}\text { High baPWV } \\
(\mathrm{n}=265)\end{array}$ & P-value \\
\hline All-causes, $n(\%)$ & $8(3.0)$ & $22(8.3)$ & 0.013 \\
Cardiovascular diseases, $n(\%)$ & $1(0.4)$ & $10(3.8)$ & 0.011 \\
$\quad$ Stroke, $n(\%)$ & $0(0.0)$ & $3(1.1)$ & 0.249 \\
Heart disease, $n(\%)$ & $1(0.4)$ & $7(2.6)$ & 0.068 \\
Malignancy, $n(\%)$ & $2(0.8)$ & $6(2.3)$ & 0.285 \\
Pneumonia, $n(\%)$ & $0(0.0)$ & $3(1.1)$ & 0.249 \\
Others, $n(\%)$ & $5(1.9)$ & $3(1.1)$ & 0.505 \\
\hline
\end{tabular}

Abbreviation: baPWV, brachial-ankle pulse wave velocity.

Figure 2 shows the ROC curves used to define the optimal cutoff value of baPWV in relation to 3-year total/cardiovascular mortality. The area under the ROC curve for total mortality was 0.673 (95\% $\mathrm{CI}=0.586-0.760$ ), and that for cardiovascular mortality was 0.795 (95\% CI $=0.701-0.890)$. The optimal cutoff value of baPWV for total mortality was $19.63 \mathrm{~m} \mathrm{~s}^{-1}$ (73\% sensitivity and 63\% specificity) and that for cardiovascular mortality was $19.63 \mathrm{~m} \mathrm{~s}^{-1}$ (91\% sensitivity and $62 \%$ specificity). A Cox proportional hazards model showed that a baPWV level $\geqslant 19.63 \mathrm{~m} \mathrm{~s}^{-1}$ was significantly associated with an increased risk of 3-year total mortality (adjusted $\mathrm{HR}=5.3,95 \%$ $\mathrm{CI}=2.2-12.7$ ) and cardiovascular mortality (adjusted $\mathrm{HR}=18.7,95 \%$ $\mathrm{CI}=2.2-157.6)$ after adjustment for age, sex and SBP. The optimal cutoff value produced higher point estimates of HRs than the cutoff at the median value.

\section{DISCUSSION}

This study showed that high baPWV was predictive of increased mortality, especially increased cardiovascular mortality, in community-
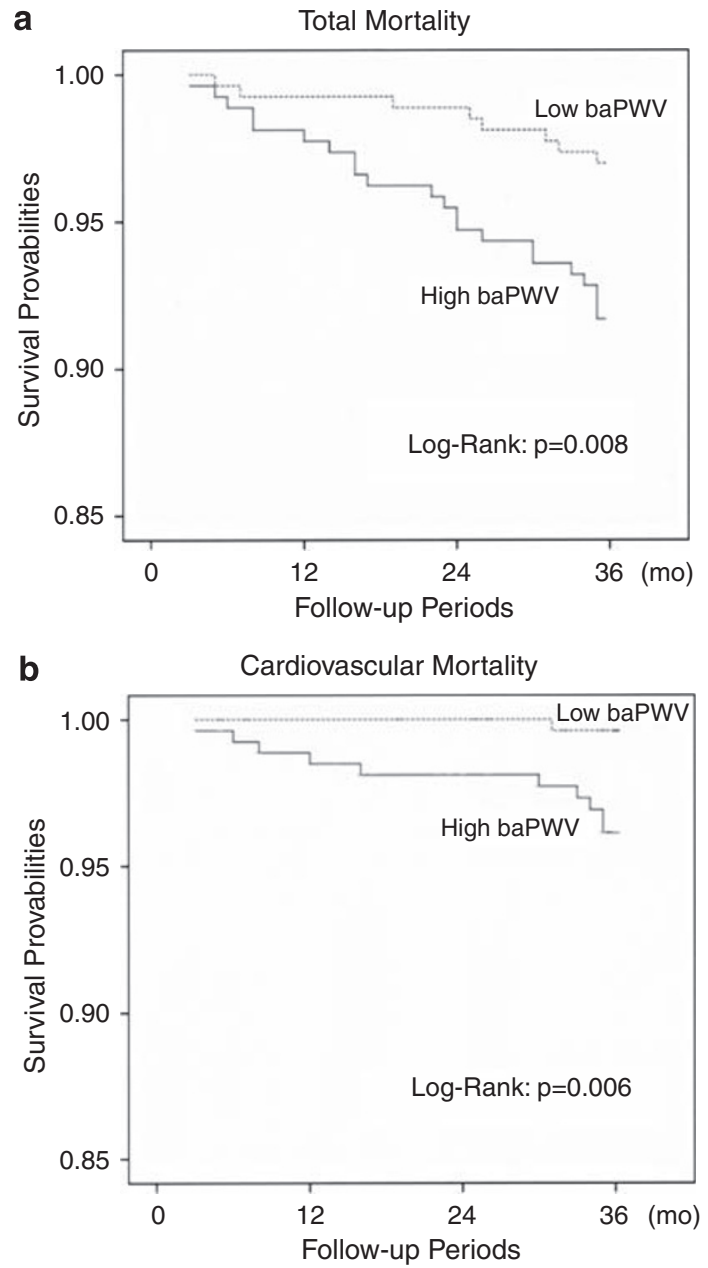

Figure 1 (a) Kaplan-Meier curves of total mortality. Survival probabilities according to brachial-ankle pulse wave velocity. (b) Kaplan-Meier curves of cardiovascular mortality. Survival probabilities according to brachial-ankle pulse wave velocity.

dwelling older adults. This finding indicates that baPWV might be a useful marker of arterial stiffness in older adults. Arterial stiffness increases with advancing age and is accompanied by structural changes to the arterial system, including fragmentation and degeneration of elastin and increases in collagen. ${ }^{1}$ An increase in arterial stiffness results in premature return of reflected waves in late systole and increases central SBP and pulse pressure. Therefore, systolic hypertension and increased pulse pressure are known to be markers of arterial stiffness and have been reported to be related to higher total/cardiovascular mortality in older adults. ${ }^{22,23}$ In this study, SBP and pulse pressure had positive correlations with baPWV (SBP: $r=0.346, P<0.01$; pulse pressure: $r=0.211, P<0.01)$. Moreover, high baPWV was associated with higher total/cardiovascular mortality, adjusted for SBP or pulse pressure. These results suggest that baPWV is a predictor of total/cardiovascular mortality independently of SBP and pulse pressure.

Aortic stiffness is closely related to total and cardiovascular mortality. ${ }^{3-10} \mathrm{cfPWV}$ is regarded to be the gold standard of aortic PWV measurement, and the association between cfPWV and cardiovascular mortality has been reported in older adults. ${ }^{7,24}$ In contrast to cfPWV measurements, which require a specialized technique, baPWV is a new method for measuring PWV that does not require a specialized technique. Four cuffs matched with oscillometric sensors are wrapped 
Table 3 The relation between baPWV and 3-year all-cause/cardiovascular mortality

\begin{tabular}{|c|c|c|c|c|}
\hline & \multicolumn{2}{|c|}{ All-cause mortality $(\mathrm{n}=30)$} & \multicolumn{2}{|c|}{ Cardiovascular mortality $(\mathrm{n}=11)$} \\
\hline & Hazard ratio $(95 \% \mathrm{Cl})$ & P-value & Hazard ratio $(95 \% \mathrm{Cl})$ & P-value \\
\hline baPWV (high/low) & $2.98(1.25-7.07)$ & 0.013 & $10.01(1.21-82.49)$ & 0.032 \\
\hline Age (1 year increased) & $1.06(1.00-1.13)$ & 0.057 & $1.14(1.04-1.25)$ & 0.006 \\
\hline Sex (men/women) & $2.23(1.06-4.68)$ & 0.034 & $2.60(0.75-9.09)$ & 0.134 \\
\hline SBP (1 mm Hg increased) & $0.99(0.97-1.01)$ & 0.270 & $0.99(0.96-1.02)$ & 0.401 \\
\hline
\end{tabular}

Abbreviations: baPWV, brachial-ankle pulse wave velocity; SBP, systolic blood pressure.
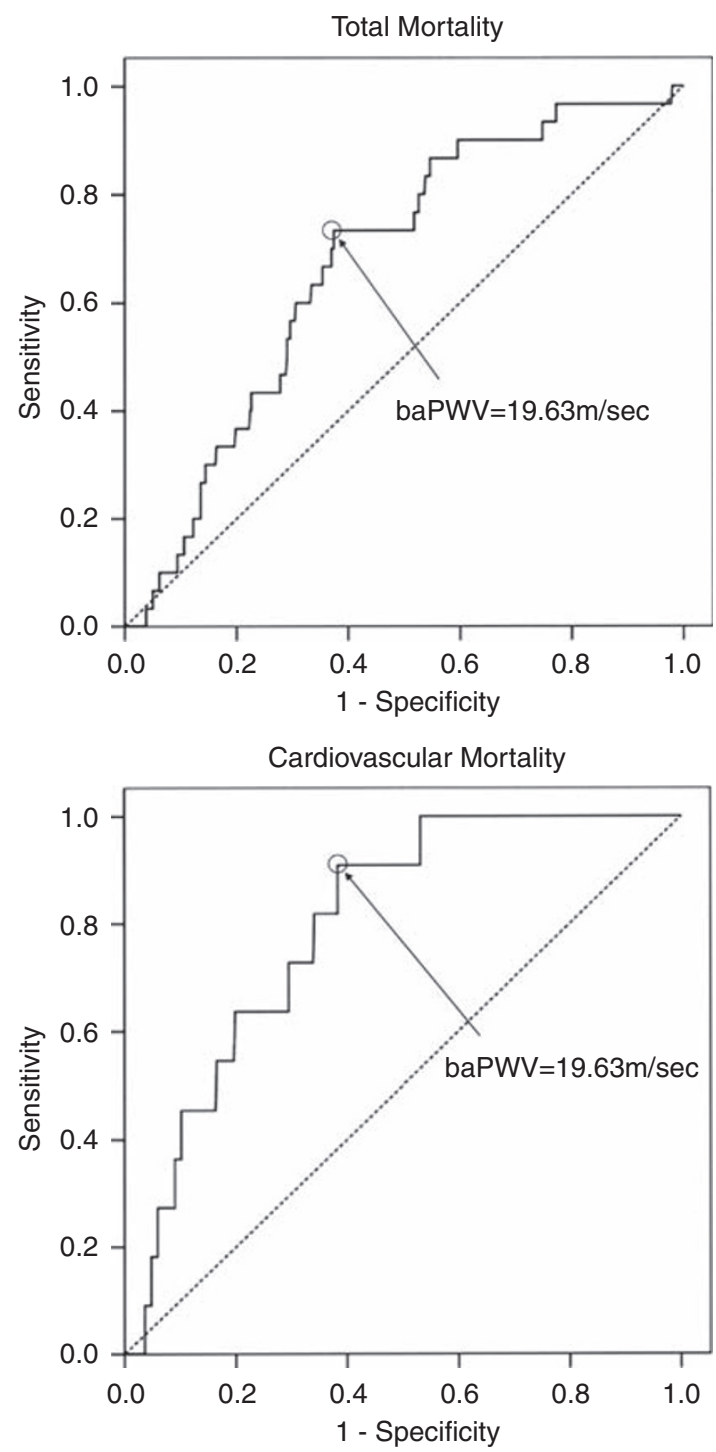

Figure 2 Receiver-operating characteristic curves to define the optimal cutoff value of baPWV in relation to 3-year total/cardiovascular mortality. Total mortality: area under the curve $=0.673(95 \% \mathrm{Cl}=0.586-0.760)$; optimal cutoff of baPWV $=19.63 \mathrm{~m} \mathrm{~s}^{-1}$ (73\% sensitivity and $63 \%$ specificity). Cardiovascular mortality: area under the curve $=0.795(95 \% \mathrm{Cl}=0.701-0.890)$; optimal cutoff of baPWV $=19.63 \mathrm{~m} \mathrm{~s}^{-1}$ (91\% sensitivity and $62 \%$ specificity).

around the upper arms and the ankles. A high reproducibility of baPWV measurements obtained with this method has been reported (correlation coefficient: interobserver reproducibility $=0.98$, intraobserver reproducibility=0.87). ${ }^{21}$ Another feature of baPWV measurements is that they yield data for both the central and peripheral arteries. baPWV has been reported to be closely correlated with aortic PWV obtained by an invasive measurement using a catheter tip manometer (correlation coefficient $=0.87)^{21}$ and with cfPWV (correlation coefficient $=0.73) .{ }^{25}$ baPWV was comparable to $\mathrm{cPPWV}$ in predicting the presence of both stroke and coronary artery disease. ${ }^{25}$

Although $12.00 \mathrm{~m} \mathrm{~s}^{-1}$ of cfPWV was recommended as a cutoff value in hypertensive patients, ${ }^{26}$ the optimal cutoff value of cfPWV in older adults has not been reported. With regard to the cutoff value of baPWV, $17.00 \mathrm{~m} \mathrm{~s}^{-1}$ was the optimal cutoff value for predicting recurrence of cardiovascular events, including coronary reintervention, reinfarction and readmission for congestive heart failure, stroke and cardiac death, in patients with history of hospitalization as a result of acute coronary syndrome. ${ }^{16}$ In addition, $18.00 \mathrm{~m} \mathrm{~s}^{-1}$ was the optimal cutoff value for predicting recurrence of cardiovascular events, including reinfarction and readmission for congestive heart failure, stroke and cardiac death in patients with acute coronary syndrome. ${ }^{16}$ This study showed the optimal cutoff value of baPWV in relation to 3 -year total/cardiovascular mortality, and it suggested that the cutoff value of baPWV in community-dwelling older adults was higher than that in clinical populations.

A potential intervention for the improvement of arterial compliance might be targeted to community-dwelling older adults with high baPWV. It was reported that 3 months of aerobic exercise and brisk walking increased central arterial compliance in middle-aged and older healthy men. ${ }^{27}$ In addition, it was reported that aortic PWV was reduced by dietary sodium restriction in healthy postmenopausal women. ${ }^{28}$ Therefore, education for changing a sedentary lifestyle and reducing sodium intake might be considered for community-dwelling older adults with high baPWV. Among the limitations of this study were the small number of participants and the short follow-up period. Consequently, the number of total deaths, including cardiovascular deaths, was small. Therefore, the analysis of the association between baPWV and prognosis, especially between baPWV and cause-specific mortality, may not be reliable. This study should thus be considered preliminary; a longitudinal study with a large cohort is necessary to confirm the relationship with long-term mortality. Second, it has been reported that antihypertensive drugs decrease baPWV, and the degree of the decrease varies according to the class of antihypertensive drug. ${ }^{29}$ Although in our study the presence or absence of on medication use was self-reported and confirmed by a physician, on the classes of antihypertensive drugs was not confirmed. A study of a population including a larger number of subjects taking distinct classes of antihypertensive drugs is necessary.

In conclusion, high baPWV was associated with higher mortality in community-dwelling older adults, indicating that noninvasive assessment of arterial stiffness by baPWV may be useful for predicting prognosis. 


\section{CONFLICT OF INTEREST}

The authors declare no conflict of interest.

\section{ACKNOWLEDGEMENTS}

This study was supported by a grant-in-aid from the Japan Arteriosclerosis Prevention Fund.

1 Lakatta EG, Levy D. Arterial and cardiac aging: major shareholders in cardiovascular disease enterprises part I: aging arteries: a 'set up' for vascular disease. Circulation 2003; 107: 139-146.

2 Cohn JN, Quyyumi AA, Hollenberg NK, Jamerson KA. Surrogate markers for cardiovascular disease, functional markers. Circulation 2004; 109(25 Suppl 1): IV-31-IV-46.

3 Blacher J, Guerin AP, Pannier B, Marchais SJ, Safar ME, London GM. Impact of aortic stiffness on survival in end-stage renal disease. Circulation 1999; 99: 2434-2439.

4 Blacher J, Asmar R, Djane S, London GM, Safar ME. Aortic pulse wave velocity as a marker of cardiovascular risk in hypertensive patients. Hypertension 1999; 33: 1111-1117.

5 Laurent S, Boutouyrie P, Asmar R, Gautier I, Laloux B, Guize L, Ducimetiere P, Benetos A. Aortic stiffness is an independent predictor of all-cause and cardiovascular mortality in hypertensive patients. Hypertension 2001; 37: 1236-1241.

6 Cruickshank K, Riste L, Anderson SG, Wright JS, Dunn G, Gosling RG. Aortic pulsewave velocity and its relationship to mortality in diabetes and glucose intolerance: an integrated index of vascular function? Circulation 2002; 106: 2085-2090.

7 Sutton-Tyrrell K, Najjar SS, Boudreau RM, Venkitachalam L, Kupelian V, Simonsick EM, Havlik R, Lakatta EG, Spurgeon H, Kritchevsky S, Pahor M, Bauer D, Newman A, Health ABC Study. Elevated aortic pulse wave velocity, a marker of arterial stiffness, predicts cardiovascular events in well-functioning older adults. Circulation 2005; 111: 3384-3390.

8 Shokawa T, Imazu M, Yamamoto H, Toyofuku M, Tasaki N, Okimoto T, Yamane K, Kohno N. Pulse wave velocity predicts cardiovascular mortality: findings from the Hawaii-Los Angeles-Hiroshima study. Circ J 2005; 69: 259-264.

9 Mattace-Raso FU, van der Cammen TJ, Hofman A, van Popele NM, Bos ML, Schalekamp MA, Asmar R, Reneman RS, Hoeks AP, Breteler MM, Witteman JC. Arterial stiffness and risk of coronary heart disease and stroke: the Rotterdam Study. Circulation 2006; 113: 657-663.

10 Hansen TW, Staessen JA, Torp-Pedersen C, Rasmussen S, Thijs L, Ibsen H, Jeppesen J. Prognostic value of aortic pulse wave velocity as index of arterial stiffness in the general population. Circulation 2006; 113: 664-670.

11 Tomiyama H, Yamashina A, Arai T, Hirose K, Koji Y, Chikamori T, Hori S, Yamamoto $Y$ Doba N, Hinohara S. Influences of age and gender on results of noninvasive brachialankle pulse wave velocity measurement-a survey of 12517 subjects. Atherosclerosis 2003; 166: 303-309.

12 Yamashina A, Tomiyama H, Arai T, Hirose K, Koji Y, Hirayama Y, Yamamoto Y, Hori S. Brachial-ankle pulse wave velocity as a marker of atherosclerotic vascular damage and cardiovascular risk. Hypertens Res 2003; 26: 615-622.

13 Imanishi R, Seto S, Toda G, Yoshida M, Ohtsuru A, Koide Y, Baba T, Yano K. High brachial-ankle pulse wave velocity is an independent predictor of the presence of coronary artery disease in men. Hypertens Res 2004; 27: 71-78.

14 Ohmine T, Miwa Y, Yao H, Yuzuriha T, Takashima Y, Uchino A, Takahashi-Yanaga F, Morimoto S, Maehara Y, Sasaguri T. Association between arterial stiffness and cerebral white matter lesions in community-dwelling elderly subjects. Hypertens Res 2008; 31: 75-81.

$15 \mathrm{Kim}$ DH, Kim J, Kim JM, Lee AY. Increased brachial-ankle pulse wave velocity is independently associated with risk of cerebral ischemic small vessel disease in elderly hypertensive patients. Clin Neurol Neurosurg 2008; 110: 599-604.
16 Tomiyama H, Koji Y, Yambe M, Shiina K, Motobe K, Yamada J, Shido N, Tanaka N, Chikamori T, Yamashina A. Brachial-ankle pulse wave velocity is a simple and independent predictor of prognosis in patients with acute coronary syndrome. Circ $J$ 2005; 69: 815-822.

17 Matsuoka O, Otsuka K, Murakami S, Hotta N, Yamanaka G, Kubo Y, Yamanaka T, Shinagawa M, Nunoda S, Nishimura Y, Shibata K, Saitoh H, Nishinaga M, Ishine M, Wada T, Okumiya K, Matsubayashi K, Yano S, Ichihara K, Cornélissen G, Halberg F, Ozawa T. Arterial stiffness independently predicts cardiovascular events in an elderly community-longitudinal investigation for the longevity and aging in Hokkaido County (LILAC) study. Biomed Pharmacother 2005; 59 (Suppl 1): S40-S44.

18 Kitahara T, Ono K, Tsuchida A, Kawai H, Shinohara M, Ishii Y, Koyanagi H, Noguchi T, Matsumoto T, Sekihara T, Watanabe Y, Kanai H, Ishida H, Nojima Y. Impact of brachialankle pulse wave velocity and ankle-brachial blood pressure index on mortality in hemodialysis patients. Am J Kidney Dis 2005; 46: 688-696.

19 Matsubayashi K, Okumiya K, Wada T, Osaki Y, Fujisawa M, Doi Y, Ozawa Y. Postural dysregulation in systolic blood pressure is associated with worsened scoring on neurobehavioral function tests and leukoaraiosis in the older elderly living in a community. Stroke 1997; 28: 2169-2173.

20 Nishinaga M, Takata J, Okumiya K, Matsubayashi K, Ozawa T, Doi Y. High morning home blood pressure is associated with a loss of functional independence in the community-dwelling elderly aged 75 years or older. Hypertens Res 2005; 28 : 657-663.

21 Yamashina A, Tomiyama H, Takeda K, Tsuda H, Arai T, Hirose K, Koji Y, Hori S, Yamamoto $Y$. Validity, reproducibility, and clinical significance of noninvasive brachialankle pulse wave velocity measurement. Hypertens Res 2002; 25: 359-364.

22 Staessen JA, Gasowski J, Wang JG, Thijs L, Den Hond E, Boissel JP, Coope J, Ekbom T, Gueyffier F, Liu L, Kerlikowske K, Pocock S, Fagard RH. Risks of untreated and treated isolated systolic hypertension in the elderly: meta-analysis of outcome trials. Lancet 2000; 355: 865-872.

23 Glynn RJ, Chae CU, Guralnik JM, Taylor JO, Hennekens CH. Pulse pressure and mortality in older people. Arch Intern Med 2000; 160: 2765-2772.

24 Meaume S, Benetos A, Henry OF, Rudnichi A, Safar ME. Aortic pulse wave velocity predicts cardiovascular mortality in subjects $>70$ years of age. Arterioscler Thromb Vasc Biol 2001; 21: 2046-2050.

25 Tanaka H, Munakata M, Kawano Y, Ohishi M, Shoji T, Sugawara J, Tomiyama H, Yamashina A, Yasuda H, Sawayama T, Ozawa T. Comparison between carotid-femoral and brachial-ankle pulse wave velocity as measures of arterial stiffness. J Hypertens 2009; 27: 2022-2027.

26 Mancia G, De Backer G, Dominiczak A, Cifkova R, Fagard R, Germano G, Grassi G, Heagerty AM, Kjeldsen SE, Laurent S, Narkiewicz K, Ruilope L, Rynkiewicz A, Schmieder RE, Boudier HA, Zanchetti A, Vahanian A, Camm J, De Caterina R, Dean V, Dickstein K, Filippatos G, Funck-Brentano C, Hellemans I, Kristensen SD, McGregor K, Sechtem U, Silber S, Tendera M, Widimsky P, Zamorano JL, Erdine S, Kiowski W, Agabiti-Rosei E, Ambrosioni E, Lindholm LH, Viigimaa M, Adamopoulos S, AgabitiRosei E, Ambrosioni E, Bertomeu V, Clement D, Erdine S, Farsang C, Gaita D, Lip G, Mallion JM, Manolis AJ, Nilsson PM, O'Brien E, Ponikowski P, Redon J, Ruschitzka F, Tamargo J, van Zwieten P, Waeber B, Williams B, Management of Arterial Hypertension of the European Society of Hypertension; European Society of Cardiology. 2007 Guidelines for the management of arterial hypertension: the task force for the management of arterial hypertension of the European Society of Hypertension (ESH) and of the European Society of Cardiology (ESC). J Hypertens 2007; 25: 1105-1187.

27 Tanaka H, Dinenno FA, Monahan KD, Clevenger CM, DeSouza CA, Seals DR. Aging, habitual exercise, and dynamic arterial compliance. Circulation 2000; 102: $1270-1275$.

28 Seals DR, Tanaka H, Clevenger CM, Monahan KD, Reiling MJ, Hiatt WR, Davy KP, DeSouza CA. Blood pressure reductions with exercise and sodium restriction in postmenopausal women with elevated systolic pressure: role of arterial stiffness. J Am Coll Cardiol 2001; 38: 506-513.

29 Takami T, Shigemasa M. Efficacy of various antihypertensive agents as evaluated by indices of vascular stiffness in elderly hypertensive patients. Hypertens Res 2003; 26: 609-614. 